\title{
Aligning Open, Physical, and Virtual Spaces in the CIS Sandbox
}

\author{
Mark Frydenberg \\ Bentley University, Computer Information Systems Department \\ Waltham, MA USA \\ mfrydenbergabentley.edu
}

\begin{abstract}
As students operate increasingly in digital environments populated by social media tools, they need to leverage them effectively to access online resources and stay connected to the physical environments which they inhabit. This paper reports on a practitioner research project to reconfigure a traditional Computer Information Systems (CIS) tutoring lab at a business university into the "CIS Sandbox." The physical facility launched with an aligned online presence intended to engage students and contribute to their learning about CIS topics. The paper presents the rationale, design, and implementation of these collaborative tools, and their impact on the students' and tutors' educational experience. Qualitative analysis from interviews with Sandbox staff and quantitative analysis of data from a preliminary survey suggests that creatively drawing upon collaborative tools and methods enables the integration between physical and virtual spaces.
\end{abstract}

Keywords: Social Media, Collaborative Learning, Learning Space, Socio-Technical Systems, Computer Lab.

\section{$1 \quad$ Introduction}

Digital students assume unlimited online resources [1], engage with social media, and learn through collaborative and informal settings [2] [3]. They tend to mix virtual with physical spaces and need creative spaces in order to develop their own innovative and technology skills. As today's world requires reliance on social technologies and being connected to the Internet, it is important to for learning spaces to provide these online opportunities for connection to augment the physical spaces where students interact.

The opportunity to renovate a university computer lab for the first time in over a decade into a collaborative learning space also presented an opportunity to build a supporting online presence based on social media and social networking tools. This paper describes how this virtual environment complements the newly renovated physical space.

In researching the design of physical and virtual learning spaces, these questions guided this study: 
- What strategies may be employed to transform a computer lab to a physical and virtual collaborative learning space?

- How can social media and Web 2.0 collaboration tools create an online presence that will promote learning both within and outside a physical computer laboratory space?

\section{From a Physical to a Virtual Learning Space}

\subsection{Rethinking Physical Learning Spaces}

Figure 1 shows the former lab prior to renovations. It is approximately 900 square feet, housed 36 desktop computers around the perimeter, and a long table at the center of the room. Networking equipment is mounted on the back wall.

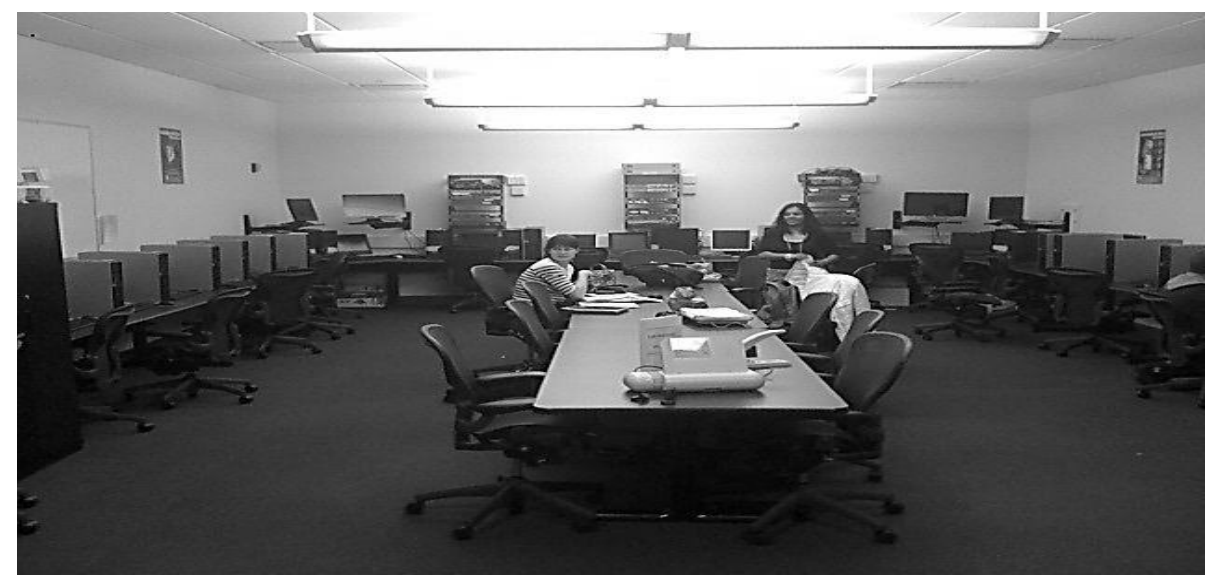

Fig. 1. Before the Renovation

Rebranded as the CIS Learning and Technology Sandbox, the new facility marks a transition from the individualized computer lab where students face the walls, to an informal space where learning takes place around tables or in a lounge setting. In engineering, "a sandbox environment consists of a controlled set of resources for trying ... new app[lication]s without the risk of damaging critical parts of the system." [4] The new name promotes discovery, learning, and a sense of playfulness within a business context. The increasing number of students who own laptops, tablets, and other mobile devices [5] pointed to the need to provide more desk space and fewer desktop computers. The renovated facility, whose physical footprint did not increase, is shown in Figure 2.

Students gather informally in an area with comfortable seating and a Google $\mathrm{TV}(1)$, engage in tutoring at tables where they can share their laptop screens on a large monitor (2), work together on diagrams on the SMART board (3), project screens on the SMART board or the back wall when giving informal demos(4), 




Fig. 2. After the Renovation

use networking equipment or one of twelve desktop computers with specialized software for CIS courses (5), and explore new technologies such as an early release of Windows 8 on a touch screen (6).

This design recognizes suggestions from the Joint Information Systems Committee [6] which advises that physical learning spaces be flexible, to accommodate both current and evolving pedagogies; future-proof, to enable space to be re-allocated and reconfigured; bold, to look beyond tried and tested technologies and pedagogies; creative, to energize and inspire learners and tutors; supportive, to develop the potential of all learners; and enterprising, to make each space capable of supporting different purposes. Several of these traits were also found in recently redesigned physical learning spaces at Rutgers University [7], University of South Carolina [8], University of Missouri [9] and other American universities, but none of these spaces also launched with an accompanying virtual presence to promote learning.

\subsection{Creating a Virtual Presence with Social Media Tools}

The CIS Sandbox is staffed by 6 graduate and 12 undergraduate students, also called tutors or lab assistants, whose responsibilities bridge supporting both the physical and virtual learning spaces. In the physical space, they perform mentoring and tutoring, and monitor equipment. Extending their roles to support a virtual space, they blog regularly, create tutorial videos, and use web-based collaboration tools to support an internal knowledge base.

The CIS Sandbox extends beyond an informal learning space located in the basement of a university classroom building; it lives online as an evolving ecosystem formed of several integrated social networking, social media and web-based collaboration tools. "Developing spaces where students can collaborate outside class provides support for an increased emphasis on teamwork, both in and outside higher education." [10] Abedin studied social patterns in computer supported collaborative learning environments and found that non-task interactions take place in computersupported collaborative learning environments, often as the result of interacting with peers in an online social environment. [11] 
Socio-technical systems consider both social and technical factors in creating evolving computer-based systems that benefit from social media and user-generated content. [12] The system includes the network of users, developers, information technology and environments in which it will be used and supported. [13] Social networks and social media tools play a significant role in the creation of sociotechnical systems. Wheeler [14] uses the term "learning space mashups" to refer to the combination of Web 2.0 and social media tools to create collaborative and reflective learning spaces. This paper uses the term "socio-technical infrastructure" to describe the relationships between social media and social networking tools, shown in Figure 3, used in the daily operation of the Sandbox.

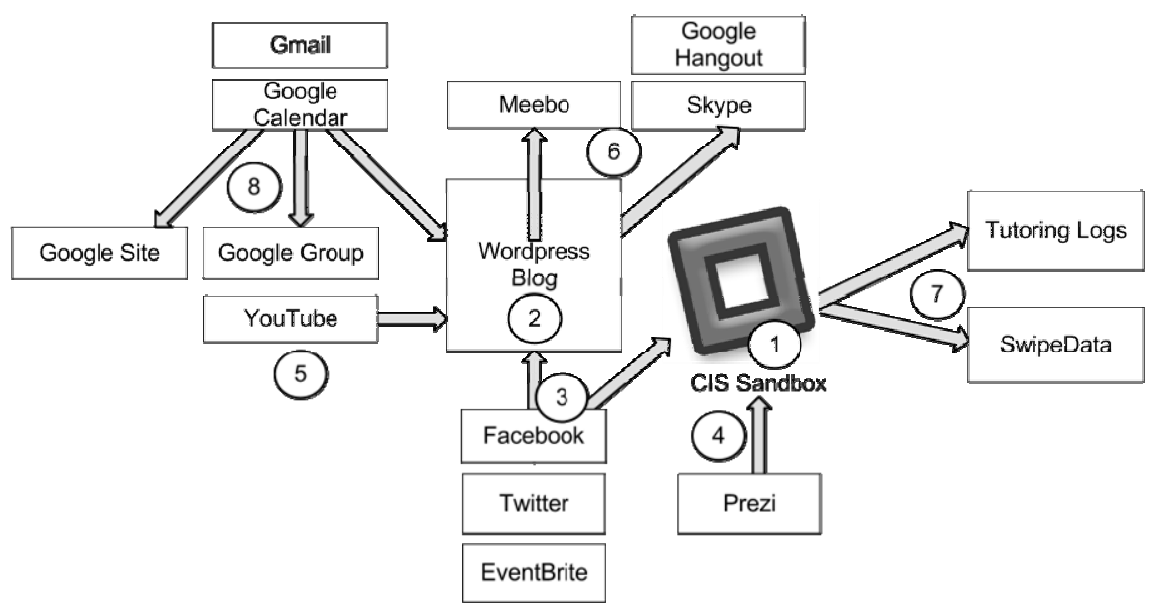

Fig. 3. Socio-Technical Infrastructure for Managing the CIS Sandbox

Each of the online tools listed promotes the physical space of the CIS Sandbox (1). The public face of the CIS Sandbox is its Wordpress blog ${ }^{1}(2)$, shown in Figure 4. It is edited by student workers who regularly post homework tips as well as articles reflecting their own interests in information technology. Facebook status updates and Twitter posts (3) occasionally report on new blog posts or special happenings in the CIS Sandbox, and add a social dimension, as students like or follow the facility. EventBrite allows visitors to sign up for special events. Prezi (4) is used to create digital signage to draw students into the physical space.

Tutors use YouTube (5) to host their original instructional videos demonstrating explanations related to course topics. Live chat with a tutor by text with Meebo or Skype, or in a Google Hangout (6) is available via a link from the Sandbox blog, providing virtual support to off-campus students and those who are unable to visit the physical location.

Upon entering, students who visit the CIS Sandbox swipe in with their ID cards. Tutors complete an online form recording their tutoring activities with students (7). Originally the tutor form was implemented as a Google Form, and later replaced with

${ }^{1}$ http: / / cis.bentley. edu/sandbox 
a custom web application, written by a student assistant, to automatically populate the form with the names of students who recently swiped in. These reports provide faculty with information about students in their classes who came for help and the type of questions they asked, and provide usage statistics, enabling the scheduling of more tutors at busier hours.

Google applications (8) facilitate the administrative management of the CIS Sandbox. A Google Site (wiki), shown in Figure 4, is the internal face of the CIS Sandbox. There, lab assistants contribute to an evolving knowledge base by documenting technology in the room, policies and procedures, and related information. They also share weekly status reports on their own "mini blog" pages within the wiki, describing their work on tutoring and special projects. Sharing status reports on an internal site allows their co-workers and supervisor to stay aware of what each lab assistant doing. In addition, it forms a permanent record that easily chronicle's a student worker's contribution over time.

Tutors keep their hours on a shared Google Calendar, whose collective content for all staff automatically populates the schedule page and front page sidebar of blog; a Google group encourages easy communication by email between assistants. This distribution list is often used to disseminate announcements, ask for shift coverage, and share information about Sandbox or campus happenings. Both the feed from the Google group and the calendar are embedded on the front page of the wiki for Sandbox staff to easily review.

By blogging on topics of interest to their peers, creating instructional videos, tutoring online, and sharing their activities on social media sites, CIS Sandbox staff extends the reach of the physical learning space into an online learning space.


Fig. 4. The CIS Sandbox blog (left) is the public face of the CIS Sandbox. The CIS Sandbox Wiki (right) houses institutional knowledge, policies, and procedures for internal use.

\section{$3 \quad$ Research Methodology}

To determine the effectiveness of the physical renovation and its virtual counterpart, a voluntary online survey was offered at the end of the Fall 2011 semester to all students who had visited the CIS Sandbox at least once during its first semester of operation. 142 of the 608 students, or $23 \%$, responded to the survey. $39 \%$ were female, $61 \%$ male. 


\subsection{Facility Usage}

Swipe data showed that 608 unique students visited 2804 times from September to December 2011. This is more than twice the number of visits during the same semester a year earlier prior to the renovation. ${ }^{2}$

129 students shared how often they visited, as shown in Figure 5.

\section{Frequency of Visits}

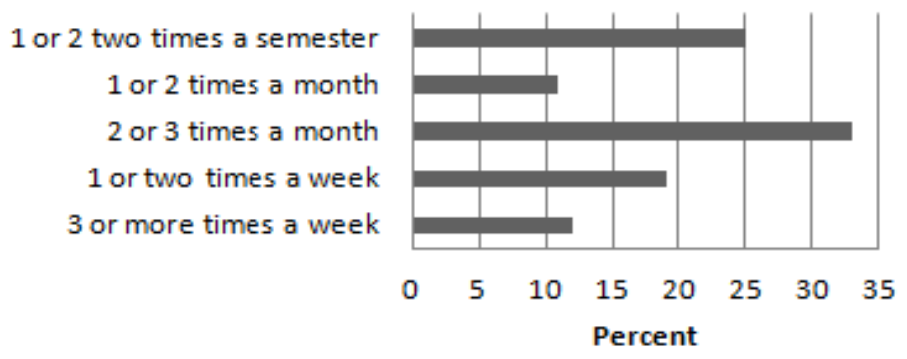

Fig. 5. Frequency of Visits to the CIS Sandbox

During its first semester, 85 of the 126 students surveyed said they had visited the blog at least once.

Figure 6 lists several technologies available in the CIS Sandbox and the number of respondents who used them during the Fall 2011 semester.

\section{Technology Use in the CIS Sandbox}



Fig. 6. Technology Use in the CIS Sandbox

Students use these technologies for both classroom and extracurricular learning. While nearly all of the students sit at the group study tables, apparently only 69 of 142 , or $49 \%$ use the large monitors for collaborative work. This may be due to the fact that instructors of programming courses prohibit students from displaying code on the

\footnotetext{
${ }^{2}$ Previously students signed in on paper, so this value is an estimate based on counting pages of signatures in a notebook.
} 
large screens when getting help with homework, so other students are not able to copy it. Students generally use the wireless networking equipment when making up an assignment that their peers completed earlier in the classroom. Some sections of the introductory IT course give extra credit assignments for students who learn to use the SMART Board, Google TVs, or Windows 8 machines. Several student assistants independently explored the Microsoft Kinect SDK to configure software demos and begin to develop their own applications.

To attract advanced and interested students to the Sandbox, Microsoft evangelists offered seminars teaching students to create xBox games and mobile applications during the Fall 2011 semester. During the Spring 2012 semester, an alumnus working for Mashable, a provider of APIs for web and mobile application development, presented about the company's web services and career opportunities. These activities, many championed by the students themselves, created occasions for learning about both course-related and extracurricular topics in the CIS Sandbox, and often resulted in creating blog posts and multimedia artifacts online.

\subsection{Aligning the CIS Sandbox's Physical and Virtual Spaces}

Users access the CIS Sandbox virtual spaces via the Sandbox blog, chat rooms and online tutoring spaces, social networking sites, and a YouTube video channel. This section describes how each of these aligns with and extends the physical space.

The Sandbox Blog. The CIS Sandbox Wordpress blog started as a way to chronicle the renovations of the physical space online and continues to evolve as a web site to inform visitors about happenings as well as a blog where lab assistants are encouraged to post approximately twice a month about frequently asked tutoring questions, hints for students, and technology interests. For example, lab assistants learning about Windows 8, the xBox and Kinect posted about these topics. Unfortunately, there is no way to understand if these posts contributed to higher use of these technology tools by other students visiting the CIS Sandbox. Figure 7 shows the number of posts in a variety of categories during the blog's first six months.

\section{Months of Sandbox Blog Content}

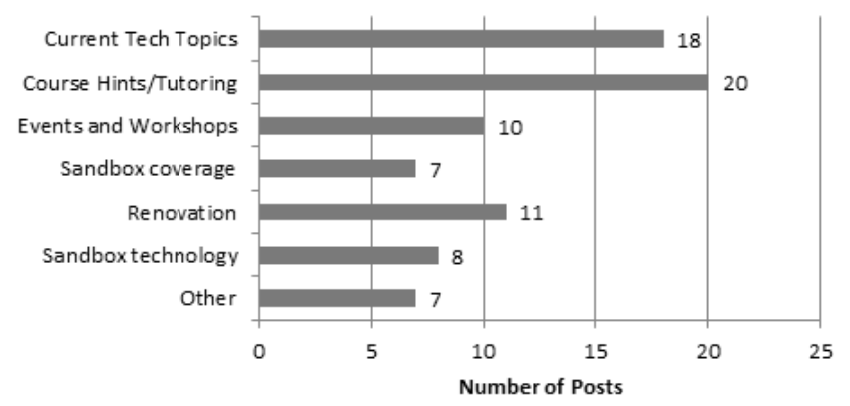

Fig. 7. Blog Posts by Category 
A snapshot from Google Analytics shown in Figure 8 suggests that the blog has generated a following, with $51 \%$ of returning visitors and $48 \%$ of new visitors during its first four months. It receives on average 100 hits per day. Visits are cyclical, with fewer visitors on weekends.

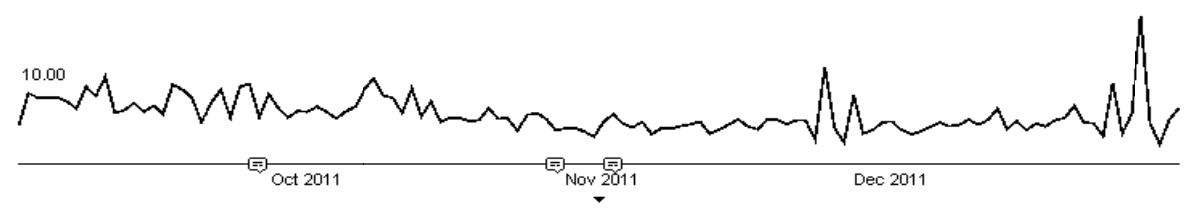

2,686 people visited this site

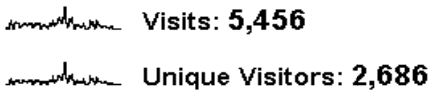

Armatheren. Pageviews: 25,561

Pages Nisit: 4.68

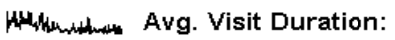

$00: 03: 33$



- $51.61 \%$ Returning Visitor

2,816 visits

口 48.39\% New Visitor

2,640 Visits

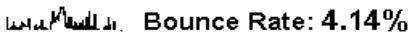

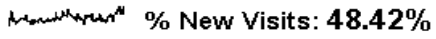

Fig. 8. Google Analytics reports on new and returning visitors

The blog is currently not open for readers to comment. Doing so would foster communication between readers and blog authors. Implementing this would require assigning a student moderator to review comments before they are posted. This change has been requested and is anticipated for a future semester.

Online Tutoring. Tutoring via Skype and screen sharing has been shown to be effective [15] [16] and the logistics of implementing this on a regular basis are currently being investigated. Several tutors have informally used these tools during the first four months of operation, and survey results suggested $62 \%$ of students surveyed would find this service useful. Social Networks. The Sandbox social media campaign got off to a slow start. Despite links on the blog to follow on Facebook and Twitter, only 34 liked the Facebook page and 14 followed @CISSandbox on Twitter during its first four months. Attempting to improve these numbers during the spring semester, some tutors encouraged students to follow the Sandbox during their tutoring sessions and distributed business cards with social media information. This raised the numbers to 115 followers on Facebook and 48 on Twitter during the following semester, but a better social media strategy is required to reach students more effectively using social networks. YouTube Videos. During the Spring 2011 semester, 4 tutors created 15 instructional videos on Excel concepts taught in an introductory IT course for which approximately 400 students are enrolled across multiple sections. Several of these videos had over 200 and as many as 255 views. ${ }^{3}$ This suggests that at

\footnotetext{
${ }^{3}$ Some faculty made these videos required viewing; others did not mention them to their students.
} 
least half of the students watched at least some of these videos. Staff also created videos of special events in the CIS Sandbox, and "how to" videos (such as how to hook up a laptop to an external monitor). All of these videos were embedded on the Sandbox blog and are available directly from the CIS Sandbox YouTube channel.

\section{Conclusion}

The CIS Sandbox has grown beyond a tutoring lab, to one where lab assistants and students can also explore their interests in technology in person and online. For students utilizing the services of the CIS Sandbox, learning occurred through in-person and online tutoring, and informally by reading the Sandbox blog, watching instructional videos, or attending extracurricular workshops.

For the lab staff, learning occurred not only on course subject matter that they were faced with explaining to their peers, but also through their own interactions with social media tools that make up the Sandbox's socio-technical infrastructure, and software applications and technologies that they investigated as part of special projects. $85 \%$ of the tutors surveyed commented that working in the CIS Sandbox enabled them to learn about IT trends and concepts beyond what is covered in their classes, and that they developed beneficial social media and technology skills that will help them in their future careers.

The integrated use of social media, social networking, and web-based collaboration tools as part of the CIS Sandbox's day-to-day operations provides opportunities for both lab staff and university students to interact with these applications, and prepares them to be productive contributors to the business world they are about to enter.

\section{References}

1. Tapscott, D.: Grown Up Digital: How the Net Generation is Changing Your World. McGraw Hill, New York (2008)

2. Andone, D., Dron, J., Boyne, C., Pemberton, L.: Digital Students Across Europe. In: World Conference on Educational Multimedia, Hypermedia, and Telecommunications, Florida, pp. 1741-1749 (2006)

3. Atwell, G.: Personal Learning Environments - the future of eLearning?, pp. 1-8 (2007)

4. Malizia, A.: Has Everything Been Invented? On Software Development and the Future of Apps. Computer 112, 110-111 (2011)

5. Smith, A.: Americans and their Gadgets, Washington, DC (2010), http: / / www . pewinternet.org/ /media//Files/Reports/2010/PIPAmericans\%20and\%20their\%20Gadgets.pdf

6. Joint Information Systems Committee: Designing Spaces for Effective Learning: A guide to 21 st century learning space design. In: Joint Information Systems Committee / Programmes/ e-Learning Innovation (2006), http://www.jisc.ac.uk/media/ documents / publications / learningspaces . pdf (accessed March 2006)

7. Rutgers University: The Alcove, http: / / alcove.rutgers.edu/

8. University of South Carolina: Technology Lounge Dedicated at Thomas Cooper Library. Reflections (Spring) 1, 3 (2010) 
9. Milne, J.: MU's Technology Lounge mimics corporate office trends. Columbia Business Times 13(25) (2007)

10. Clayton-Pederson, A., O'Neill, N.: Curricula Designed to Meet 21st Century Expectations. In: Educating the Net Generation, Educause, Boulder (2005),

http: / /www. educause. edu/educatingthenetgen

11. Abedin, B.: Investigating the Trend of Non-Task Social Interactions in Online Collaborative Learning Environments. In: Proceedings of the 44th Hawaii International Conference on System Sciences, p. 108 (2011)

12. Baxter, G., Sommerville, I.: Socio-technical systems: From design methods to system engineering. International Journal of Human-Computer Studies, 1-33 (November 2008)

13. Scacchi, W.: Socio-Technical Design. In: The Encyclopedia of Human-Computer Interaction, Yorkshire Publishing Group, Yorkshire (2004)

14. Wheeler, S.: Learning Space Mashups: Combining Web 2.0 Tools to Create Collaborative and Reflective Learning Spaces. Future Internet, 3-13 (2009), http: / / www . mdpi.com/1999-5903/1/1/3/

15. Staupe, A., Kolas, L.: Online interactive learning arena over the internet. In: Proceedings of the Sixth Conference on IASTED International Conference Web-Based Education, Anaheim, vol. 2, pp. 276-281 (2007), http://dl.acm.org.ezp.bentley.edu/citation. cfm?id=1323159.13 $23208 \& C O I l=D L \& d l=G U I D E \& C F I D=67263778 \& C F T O K E N=60224140$

16. Sivula, M.: Using Skype as an Academic Tool: Lessons Learned. eLearn (7) (July 2011), http: // elearnmag.acm.org.ezp. bentley.edu/archive.cfm?aid=201 1843 